48

Content list available at: https://openbiomarkerjournal.com

RESEARCH ARTICLE

\title{
Plasma Fibrinogen as a Biomarker of Stable and Exacerbated Chronic Obstructive Pulmonary Disease
}

\author{
Kashifa Ehsan ${ }^{1, *}$, Sibgha Zulfiqar ${ }^{1}$, Amber Hassan ${ }^{2}$ and Humaira Waseem ${ }^{2}$ \\ 'Federal Post Graduate Medical Institute (FPGMI), Sheikh Zayed, Lahore, Pakistan \\ ${ }^{2}$ Faculty of Allied Health Sciences, Research Unit, The University of Lahore, Lahore, Pakistan
}

\begin{abstract}
:
Study Design:

An experimental, comparative, cross-sectional study

Place and Duration of Study:

Department of Physiology, Federal Post Graduate Medical Institute (FPGMI), Sheikh Zayed Medical Complex Lahore, Pakistan from August 2013 to 2014

Background:

Chronic Obstructive Pulmonary Disease (COPD) is a preventable and treatable disease, but is a partially reversible chronic inflammatory condition characterized by airway obstruction. COPD remains under-diagnosed and under-treated because the only available diagnostic method at present is testing lung functions by spirometry which is not helpful to determine the severity and clinical outcomes of the disease. Circulating biomarkers are under consideration for various diseases worldwide. Plasma fibrinogen is emerging as one of the most promising biomarkers of COPD in smokers.

\section{Objective:}

The objective of this study is to investigate if plasma fibrinogen can serve as a diagnostic biomarker of COPD in smokers, and if its further higher levels are seen in the exacerbated state of the disease in comparison to the stable disease.

\section{Materials and Methods:}

75 middle-aged to old-age smokers of either gender were selected. Lung functions of every participant were measured to determine Forced Expiratory Volume in the first second (FEV1), Forced Vital Capacity (FVC), and the ratio of FEV1/FVC by spirometry. On the basis of the results of the tests, subjects were divided into three groups; firstly, the control group of chronic smokers without COPD, secondly, smokers with COPD in a stable state, and thirdly, patients in an exacerbated state of COPD. Plasma fibrinogen was quantitatively estimated in every individual of all three groups by the Clauss method using the Hemostat Fibrinogen kit.

Results:

The average Plasma fibrinogen level was found to be $235.008 \mathrm{mg} / \mathrm{dl}$ in healthy smokers (control group), while an average of $440.12 \mathrm{mg} / \mathrm{dl}$ was measured in patients with stable COPD. The difference in plasma fibrinogen levels was found to be significant, having a p-value of $(0.000)$. In the third group with declined lung function predicting acute exacerbated COPD, fibrinogen was found to be $>453.2 \mathrm{mg} / \mathrm{dl}$, which was significantly higher than in the stable disease group ( $p$-value $>0.0017$ )

Conclusion:

Plasma fibrinogen level measurement is a reliable and accessible test in terms of a diagnostic marker of COPD, as compared to conventional lung function testing done in the past.
\end{abstract}

Keywords: Smokers, Chronic Obstructive Pulmonary Disease (COPD), Plasma fibrinogen level, Lung function testing by spirometry FEVI, FEV1/FVC ratio, Inflammatory biomarker. 


\section{INTRODUCTION}

Chronic Obstructive Pulmonary Disease (COPD) is defined as a multicomponent, preventable, treatable, partially irreversible chronic inflammatory, respiratory disease with extra pulmonary manifestations. It is characterized by progressive and persistent airflow limitation, usually resulting from the chronic inflammatory reaction of smaller airways due to tobacco smoking and other inhaled toxins $[1,2]$. COPD has different phenotypes and is believed to encompass a spectrum of diseases, such as "emphysema," destruction of gas-exchange area of alveoli at one end, and "chronic bronchitis" at the other, which may precede or follow COPD [3, 4]. This disease, unfortunately, remains underdiagnosed or misdiagnosed since most of the time, it is considered to be the same airway obstruction that is seen in bronchial asthma. COPD and asthma can easily be differentiated by the variability of the airflow obstruction in asthma due to the hypersensitive allergic response of airways to any foreign agent (i.e., exacerbations). COPD is a chronic disease with slow progression, and obstruction remains in the stable state markedly over several months. Although the same structural changes are seen in both ailments, there are some obvious differences in airway functioning [5]. COPD can be classified as stable or exacerbated COPD on the basis of disease severity, clinical presentation, and lung function tests by spirometry [6, 7]. Cigarette smoking is the strongest risk factor in the development of COPD worldwide, and the current knowledge on COPD and its associated morbidity and mortality comes from those analyses which are made in smoking-related COPD $[8,9]$. The smoking burden is usually measured in pack-year, and to calculate the pack-year, smokers are asked to report the average number of cigarettes smoked per day in the duration in years. One pack-year means smoking an average of one pack (20 cigarettes) every day for one complete year [10]. The packyears calculation assumes the same weightage for both duration of smoking and cigarettes/day though the relative contribution of the duration of smoking versus cigarettes/day toward COPD is not known [11]. The current strategy to diagnose COPD on clinical grounds or additionally by the measurement of respiratory functions by spirometry potentially leaves many patients underdiagnosed and sometimes over-diagnosed. Globally, 10 - 95\% under-diagnosis and $5-60 \%$ overdiagnosis of disease are prevalent due to the unavailability of spirometry in rural areas of the developing countries, untrained technical operators to perform the test, and their lack of skill in interpretating the results of spirometry $[12,13]$. The diagnosis of COPD can only be declared if patients have a combination of certain symptoms, "a post-bronchodilator fixed ratio of Forced Expiratory Volume in $1^{\text {st }}$ second and Forced Vital Capacity, i.e., FEV1/FVC $<0.7$, measured by spirometry [14]. Hence in the absence of any reliable and accurate diagnostic criteria, there is a dire need to search for some authenticated markers for the diagnosis of COPD. Effective therapeutic interventions are not possible without a proper and accurate diagnosis of any disease. Conversely, an overdiagnosis or false-positive diagnosis may also cause the true underlying

\footnotetext{
* Address correspondence to this author at the Federal Post Graduate Medical Institute (FPGMI), Sheikh Zayed, Lahore, Pakistan;

E-mail: kashifamimi@gmail.com
}

diagnosis to be missed. Therefore, it has been hypothesized that to diagnose COPD and its clinical progression, biomarkers should be searched as a suitable substitute for previously used diagnostic tools [15]. Various body compartments like breath condensate, blood, sputum, bronchoalveolar lavage, and urine as samples are tested for the detection of biomarkers. CCL-18, Surfactant protein-D (SP-D), CC-16 (Clara cell protein-16), MMPs 8 and 9 (matrix metalloproteinase), IL-6 and 8 (Interleukin), and CRP (C-reactive protein) are distinguishable blood biomarkers which are considered to be the potential diagnostic markers for COPD, but none of them has been proved to be significant in this context $[16,17]$. Amongst all other biomarkers under consideration, fibrinogen is found to play a pivotal role in diagnosing COPD. Fibrinogen is glycoprotein, which is synthesized in hepatocytes and serves as an essential coagulation factor when released into blood circulation. In COPD, the inflammatory role of fibrinogen as an acute-phase reactant makes it an ideal biomarker [18, 19]. Fibrinogen, an inflammatory marker, is found to be increased not only due to coagulation but also following a tissue injury. The plasma levels of fibrinogen proved to be a predictor of acute exacerbations of COPD as well [20]. Plasma fibrinogen levels, along with other factors like blood cells, may predict the frequency of the attack and clinical phenotype of COPD; frequency of exacerbations of disease is also determined by these biomarkers [21].

The comprehensive meta-analysis of different observational studies though proved the hypothesis of circulating fibrinogen as a biomarker, but still, nearly all qualified studies are measuring the circulating fibrinogen concentration only once, and there is no long-term change evaluation in the development of COPD. Furthermore, measurement bias is also suspected because no identical method is used to assay circulating fibrinogen across studies. Thereby, future well-performed studies on larger scales are suggested for drawing a conclusion, and for refusing or confirming our findings [19].

In almost all components of the disease (progression, severity, associated co-morbidities, mortality, diagnosis, and treatment strategies), plasma fibrinogen levels show a significant correlation with COPD. An inverse relationship was found between baseline fibrinogen levels and pulmonary functions, i.e., if fibrinogen is higher than normal at the beginning of COPD, declined FEV1 and FVC will be observed over the course of the disease [22]. This difference was observed in current smokers and non-smokers as well. Moreover, higher baseline fibrinogen levels were also associated with an increased incidence of admissions with an exacerbation of COPD. It has been studied that there is a promising relationship between raised plasma fibrinogen at baseline in individuals with COPD and the development of frequent exacerbations of disease and hospitalization as well [23].

\section{METHODOLOGY}

A comparative cross-sectional study was conducted in the Physiology Department of Sheikh Zayed Postgraduate Medical Institute, Sheikh Zayed Hospital Pulmonology Department, 
Lahore, in collaboration with the Combined Military Hospital. The total 75 patients were divided into 3 groups (controls $=25$, exacerbated $=25$ and stable $\mathrm{COPD}=25$ patients). Gender matched, young adults (20 - 39 years of age) to old aged (60 80 years of age) individuals with a history of smoking at least 10 pack-years $(20$ cigarettes/day for 1 complete year $=1$ packyear) were included in the three groups. All the normal and healthy individuals without a history of COPD were included as controls. Patients diagnosed with COPD according to GOLD criteria, having a history of smoking of more than 10 packyears ( 20 cigarettes/ day for 1 complete year $=1$ pack year $)$ and a state of exacerbation free period of 3-4 months, were enrolled as stable cases. Patients with diagnosed COPD in an exacerbated state, having a history of acute attacks in the last few days to 1 week,presented in the emergency department or already hospitalized, were enrolled as exacerbated cases. The exclusion criteria included diagnosed cases of asthma or other chronic respiratory diseases on the basis of spirometric findings, patients with history of malignancy or serious comorbidities that would prevent the study completion and patients diagnosed with active pulmonary tuberculosis or bronchiectasis due to old complicated TB. The study was started after the approval from the Ethical Review Board of Federal Post Graduate Medical Institute Sheikh Zayed Medical Complex Lahore. Data including name, age, weight, height, history of smoking, and other diseases in the past were recorded through a questionnaire. A detailed present and past history were recorded, and a physical examination was performed. A 6-minute walk test was performed to measure the grading of dyspnoea on all the participants except those who were unable to take a single step due to shortness of breath (exacerbated COPD cases). After observing all aseptic measures, $3 \mathrm{cc}$ of blood was obtained from the cubital vein using venepuncture in $3.2 \%$ sodium citrate containing vial. The plasma was separated from blood by centrifugation at the rate of 5000 revolutions per minute for 10 minutes. It was then stored in an aliquot and kept frozen at $-20 \mathrm{C}$ till the required test was performed. The test was then conducted by indirect coagulation clauss method in haematology laboratory of Combined Military Hospital Lahore after due permission from the authorities. A human Hemostat fibrinogen kit was used for the estimation of fibrinogen levels

The obtained data was entered and analysed by using SPSS 22.0. The data for quantitative variables, i.e., age, BMI, smoking pack years, FEV1, FEV1/FVC, FEV1 pp, fibrinogen levels in blood and the qualitative variables, i.e., grading of dyspnoea and gold staging of COPD were described by using descriptive statistics, i.e., mean $\pm \mathrm{SD}$ for the three groups. The comparison of these variables among groups was studied by using one-way ANOVA; p-value of $\leq 0.05$ was considered significant.

\section{RESULTS}

In control group, the majority of the patients were adults $(12(80 \%))$ and middle-aged (11 (44\%)), having normal weight (13 (52\%)) and smoking $10-12$ packs of cigarettes per year (19 $(76.0 \%))$. In the exacerbated group, the majority of the patients were middle aged $(17(68 \%))$, having normal BMI (16 $(64 \%))$ and smoking 21 - 40 packs of cigarette per year. In the stable COPD group, the majority of the patients were old aged (12 (16\%)), having normal BMI (18 (72\%)) and smoking 10 12 packs of cigarette per year (Tables 1.1-1.3).

Table 1.1. This table represents the groups division for this study.

\begin{tabular}{|c|c|c|c|}
\hline \multicolumn{4}{|c|}{ Groups } \\
\hline Variables & Control & Exacerbated & Stable \\
\hline Adults (15 - 40) & $12(80 \%)$ & $1(4 \%)$ & $8(32 \%)$ \\
\hline Middle aged (41 - 60) & $11(44 \%)$ & $17(68 \%)$ & $5(20 \%)$ \\
\hline
\end{tabular}

Table 1.2. Body Mass Index.

\begin{tabular}{|c|c|c|}
\hline \multicolumn{3}{|c|}{ BMI } \\
\hline Underweight & $4(12 \%)$ & $4(16 \%)$ \\
\hline Normal & $13(52 \%)$ & $16(64 \%)$ \\
\hline Overweight & $8(32 \%)$ & $5(20 \%)$ \\
\hline
\end{tabular}

Table 1.3. Personal history of patients.

\begin{tabular}{|c|c|c|c|}
\hline \multicolumn{4}{|c|}{ Smoking Status } \\
\hline 10 - 12 Packs per year & $19(76.0 \%)$ & $8(32 \%)$ & $17(68 \%)$ \\
\hline 21 - 30 Packs per year & $4(16 \%)$ & $6(24 \%)$ & $6(24.0 \%)$ \\
\hline 31 - 40 Packs per year & $2(8 \%)$ & $10(40 \%)$ & $1(4.0 \%)$ \\
\hline$>$ 40 Packs per year & $0(0 \%)$ & $1(4.0 \%)$ & $1(4.0 \%)$ \\
\hline
\end{tabular}

\subsection{Clinical History of Patients}

According to Tables 2.1-2.4, in the control group, the majority of the patients had grade 2 dyspnea, low FEV1 (Below 3 L) (16 (64\%)) and normal FEV/FVC (24 (96\%)). In the exacerbated group, the majority of the patients had grade 4 dyspnea $(21(84 \%))$, stage 3 COPD $15(60 \%)$, very low (Below $1 \mathrm{~L})(21(84 \%))$ and low FEV1/FVC $(19(76 \%))$. In the stable COPD group, the majority of the patients had G3 dyspnea (19 $(76 \%))$, stage 1 of COPD $(18(72 \%))$, FEV1 Low (Below 2 L) $(19(76 \%))$ and Very low FEV1/FVC $(20(80 \%))$.

\section{Table 2.1. This table shows the Grading of Dyspnea.}

\begin{tabular}{|c|c|c|c|}
\hline \multicolumn{4}{|c|}{ Grading of Dyspnea } \\
\hline G1 & $7(28 \%)$ & $0(0 \%)$ & $0(0 \%)$ \\
\hline G2 & $16(64 \%)$ & $1(4 \%)$ & $4(16 \%)$ \\
\hline G3 & $2(8 \%)$ & $3(12 \%)$ & $19(76 \%)$ \\
\hline G4 & $0(0 \%)$ & $21(84 \%)$ & $2(4 \%)$ \\
\hline
\end{tabular}

Table 2.2. This table shows the stages of COPD.

\begin{tabular}{|l|c|c|c|}
\hline \multicolumn{4}{|c|}{ Stages of COPD } \\
\hline Stage 1 & $0(0 \%)$ & $0(0 \%)$ & $18(72 \%)$ \\
\hline Stage 2 & $0(0 \%)$ & $5(20 \%)$ & $3(12 \%)$ \\
\hline Stage 3 & $0(0 \%)$ & $15(60 \%)$ & $4(16 \%)$ \\
\hline Stage 4 & $0(0 \%)$ & $5(20 \%)$ & $0(0 \%)$ \\
\hline
\end{tabular}

Table 2.3. This table represents Forced Expiratory Volume in 1 second (FEV1).

\begin{tabular}{|c|c|c|c|}
\hline \multicolumn{4}{|c|}{ Forced Expiratory Volume in 1 second (FEV1) } \\
\hline Normal (3 - 4 L) & $7(28 \%)$ & $0(0 \%)$ & $0(0 \%)$ \\
\hline Low (Below 3 L) & $16(64 \%)$ & $1(4 \%)$ & $4(16 \%)$ \\
\hline Low (Below 2 L) & $2(8 \%)$ & $3(12 \%)$ & $19(76 \%)$ \\
\hline Very Low (Below 1 L) & $0(0 \%)$ & $21(84 \%)$ & $2(8 \%)$ \\
\hline
\end{tabular}


Table 2.4. The table represents the results of FEV1/FVC.

\begin{tabular}{|c|c|c|c|}
\hline \multicolumn{4}{|c|}{ FEV1/FVC } \\
\hline Normal $(>\mathbf{8 0})$ & $24(96 \%)$ & $1(4.0 \%)$ & $0(0.0 \%)$ \\
\hline Low (<80) & $1(4.0 \%)$ & $19(76 \%)$ & $5(20 \%)$ \\
\hline Very low (<60) & $0(0.0 \%)$ & $5(20 \%)$ & $20(80 \%)$ \\
\hline
\end{tabular}

Plasma fibrinogen levels were compared among the three groups. Mean \pm SD of plasma fibrinogen levels were $453.24 \pm$ $81.92 \mathrm{mg} / \mathrm{dl}$ in the exacerbated COPD group, $400.12 \pm 81.45$ $\mathrm{mg} / \mathrm{dl}$ in the stable COPD group, and $235.01 \pm 45.015$ in the healthy controls. It was seen that plasma fibrinogen levels were raised in patients in an exacerbated state of COPD and also in patients having stable COPD $(\mathrm{p}$-value $=0.000)($ Fig. 1).

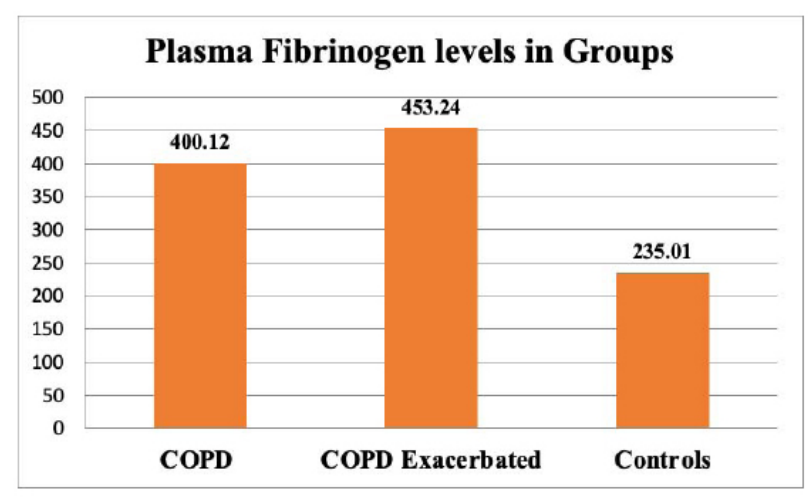

Fig (1). Comparison of plasma Fibrinogen levels in stable COPD, exacerbated and control group ( $\mathrm{p}$-value $<.0001^{*}$ ).

\section{DISCUSSION}

The aim of this research work was to determine a diagnostic biomarker for a misdiagnosed and consequently wrongly treated disease of COPD; for this purpose, plasma fibrinogen was considered a surrogate endpoint biomarker. The association of plasma fibrinogen levels with COPD and its severity was examined in 75 individuals who were smokers, and 50 of them were confirmed patients of COPD, diagnosed by their reduced pulmonary functions. The key finding of this experimental work suggests that a significant, concentrationdependent relation exists between COPD and its increasing severity and higher circulating fibrinogen. Fibrinogen in the human body is a plasma protein synthesized in the liver mainly; it is converted into fibrin during blood coagulation [24]. It has been observed that fibrinogen synthesis is upregulated as a major acute-phase reactant in response to inflammation, and this is a major clinical feature of COPD [25]. In addition, evidence also exists that the risk of exacerbation of COPD is increased with elevated fibrinogen plasma [26]. Furthermore, fibrinogen concentration is correlated with impaired lung functions and is related to increased mortality among patients with COPD [27]. Plasma fibrinogen is hence reasonably speculated as a promising clinical biomarker in predicting the risk and severity of COPD [28]. Based on various meta-analyses, a significant relationship between severity of COPD and circulating fibrinogen has been established [29 - 34]. Another important fact is a possible interaction between cigarette smoking and plasma fibrinogen. Amongst the established risk factors for the development of
COPD, cigarette smoking and its contribution to COPD disease is interestingly found to be mediated by elevated plasma fibrinogen, which though could not be reliably investigated in the present study due to the unreliable history of individual participants of the study, yet we agree that further explorations on the fact are needed. Importantly, plasma fibrinogen is a biomarker that is easy to assay and can be easily proposed as a more practical and useful approach toward clinical management of COPD. There are certain limitations of the study; firstly, it is a cross-sectional study with a small sample size, therefore, there are fair chances that it might have affected the analysis of statistical power of the results. Multiple prospective and extensive studies on COPD patients have been conducted worldwide, but still, in Asians, no significant research has been done. Secondly, plasma fibrinogen concentration was only measured once, therefore, we could not evaluate the long-term effects of the change of fibrinogen on the progression of COPD. Thirdly, the usefulness of fibrinogen levels could not be investigated for predicting mortality with COPD. Thereby, drawing a conclusion is not possible until some longitudinal, large-scale, and well-performed studies confirm or refuse the results of our study.

\section{CONCLUSION}

The plasma inflammatory biomarker profile, identified in patients with COPD in a stable and exacerbated state, represents a valuable tool for the replacement of lung function testing in the assessment and clinical presentation of COPD. The need for biomarkers to identify the heterogeneity of COPD and characterize and continuously improve the identification of disease progressors is mandatory for the efficient management of the disease. Our study is the first research on the population of Pakistan to consider plasma biomarker fibrinogen level as a significant indicator for COPD. We have concluded that easy to assay, plasma fibrinogen levels may serve as a useful marker for earlier detection of the potential causes of COPD. If measured prospectively during close follow-up, fibrinogen levels can serve as a prognostic marker as well. Consequently, plasma fibrinogen will help in improving the clinical outcome and for the effective treatment of COPD.

\section{ETHICS APPROVAL AND CONSENT TO PARTI- CIPATE}

This study has been approved by the institutional review board of the 'Federal PostGraduate Medical Institute, Sheikh Zayed Hospital National Health Research Complex Lahore, Pakistan. (Registration number: Institutional Review Board, Ref No: F-39/NHRC/Admin/IRB/86 IRB No:1274).

\section{HUMAN AND ANIMAL RIGHTS}

No Animals were used in this research. All human research procedures followed were in accordance with the ethical standards of the committee responsible for human experimentation (institutional and national), and with the Helsinki Declaration of 1975, as revised in 2013.

\section{CONSENT FOR PUBLICATION}

Patients were informed about this study. 


\section{AVAILABILITY OF DATA AND MATERIALS}

The data supporting this study is present within the manuscript.

\section{FUNDING}

None.

\section{CONFLICT OF INTEREST}

The authors declare no conflict of interest financial or otherwise.

\section{ACKNOWLEDGEMENTS}

Declared none.

\section{REFERENCES}

[1] Patel AR, Patel AR, Singh S, Singh S, Khawaja I. Singh S, Singh S, Khawaja I. Global initiative for chronic obstructive lung disease: the changes made. Cureus 2019; 11(6): e4985.

[http://dx.doi.org/10.7759/cureus.4985] [PMID: 31453045]

[2] Celli BR, Wedzicha JA. Update on clinical aspects of chronic obstructive pulmonary disease. N Engl J Med 2019; 381(13): 1257-66. [http://dx.doi.org/10.1056/NEJMra1900500] [PMID: 31553837]

[3] Criner GJ, Martinez FJ, Aaron S, et al. Current controversies in chronic obstructive pulmonary disease. A report from the global initiative for chronic obstructive lung disease scientific committee. Ann Am Thorac Soc 2019; 16(1): 29-39.

[http://dx.doi.org/10.1513/AnnalsATS.201808-557PS] [PMID: 30427736]

[4] Yormaz B, Cebeci H, Yılmaz F, Süerdem M. Bone mineral density in emphysema and chronic bronchitis phenotypes in hospitalized male chronic obstructive pulmonary disease patients. Clin Respir J 2020; 14(1): 47-53.

[http://dx.doi.org/10.1111/crj.13099] [PMID: 31628822

[5] Karayama M, Inui N, Yasui H, et al. Physiological and morphological differences of airways between COPD and asthma-COPD overlap. Sci Rep 2019; 9(1): 7818.

[http://dx.doi.org/10.1038/s41598-019-44345-6] [PMID: 31127165]

[6] Rhee CK, Chau NQ, Yunus F, Matsunaga K, Perng DW. Management of copd in asia: a position statement of the asian pacific society of respirology. Respirology 2019; 24(10): 1018-25. [http://dx.doi.org/10.1111/resp.13633] [PMID: 31276272]

[7] Burge S, Wedzicha JA. COPD exacerbations: definitions and classifications. Eur Respir J Suppl 2003; 41(41)(Suppl.): 46s-53s. [http://dx.doi.org/10.1183/09031936.03.00078002] [PMID: 12795331]

[8] Caramori G, Adcock IM, Papi A. Clinical definition of COPD exacerbations and classification of their severity. South Med J 2009; 102(3): 277-82.

[http://dx.doi.org/10.1097/SMJ.0b013e3181836b73] [PMID: 19204646]

[9] Radovanovic D, Contoli M, Marco FD, et al. Clinical and functional characteristics of COPD patients across GOLD classifications: results of a multicenter observational study. COPD 2019; 16(3-4): 215-26. [http://dx.doi.org/10.1080/15412555.2019.1659760] [PMID: 31500459]

[10] Soumagne T, Guillien A, Roche N, et al. In patients with mildtomoderate copd, tobacco smoking, and not copd, is associated with a higher risk of cardiovascular comorbidity. Int $\mathrm{J}$ Chron Obstruct Pulmon Dis 2020; 15: 1545-55.

[http://dx.doi.org/10.2147/COPD.S253417] [PMID: 32669840]

[11] Volk RJ, Mendoza TR, Hoover DS, Nishi SPE, Choi NJ, Bevers TB. Reliability of self-reported smoking history and its implications for lung cancer screening. Prev Med Rep 2020; 17: 101037. [http://dx.doi.org/10.1016/j.pmedr.2019.101037] [PMID: 31934536]

[12] Bhatt SP, Kim YI, Harrington KF, et al. Smoking duration alone provides stronger risk estimates of chronic obstructive pulmonary disease than pack-years. Thorax 2018; 73(5): 414-21. [http://dx.doi.org/10.1136/thoraxjnl-2017-210722] [PMID: 29326298]

[13] Ho T, Cusack RP, Chaudhary N, Satia I, Kurmi OP. Under- and overdiagnosis of COPD: a global perspective. Breathe (Sheff) 2019; 15(1): 24-35. [http://dx.doi.org/10.1183/20734735.0346-2018] [PMID: 30838057]

[14] Abad-Arranz M, Moran-Rodríguez A, Mascarós Balaguer E, et al. Quantification of inaccurate diagnosis of COPD in primary care medicine: an analysis of the COACH clinical audit. Int J Chron Obstruct Pulmon Dis 2019; 14: 1187-94.

[http://dx.doi.org/10.2147/COPD.S199322] [PMID: 31239656]

[15] Ruparel M, Quaife SL, Dickson JL, et al. Prevalence, symptom burden and under-diagnosis of chronic obstructive pulmonary disease in a lung cancer screening cohort. Ann Am Thorac Soc 2020; 17(7): 869-78.

[http://dx.doi.org/10.1513/AnnalsATS.201911-857OC]

[PMID: 32164439

[16] Paone G, Leone V, Conti V, et al. Blood and sputum biomarkers in COPD and asthma: a review. Eur Rev Med Pharmacol Sci 2016; 20(4): 698-708 [PMID: 26957273]

[17] Mathioudakis AG, Janssens W, Sivapalan P, et al. Acute exacerbations of chronic obstructive pulmonary disease: in search of diagnostic biomarkers and treatable traits. Thorax 2020; 75(6): 520-7.

[http://dx.doi.org/10.1136/thoraxjnl-2019-214484] [PMID: 32217784]

[18] Stockley RA, Halpin DMG, Celli BR, Singh D. Chronic obstructive pulmonary disease biomarkers and their interpretation. Am J Respir Crit Care Med 2019; 199(10): 1195-204

[http://dx.doi.org/10.1164/rccm.201810-1860SO] [PMID: 30592902]

[19] Zhou B, Liu S, He D, et al. Fibrinogen is a promising biomarker for chronic obstructive pulmonary disease: evidence from a meta-analysis. Biosci Rep 2020; 40(7): BSR20193542.

[http://dx.doi.org/10.1042/BSR20193542] [PMID: 32677669]

[20] Hyun DG, Lee JH, Oh YM, Lee SW, Lee SD, Lee JS. Association of plasma fibrinogen concentrations and blood eosinophil counts with clinical phenotypes of COPD. Int J Tuberc Lung Dis 2019; 23(9): 1035-41.

[http://dx.doi.org/10.5588/ijtld.18.0630] [PMID: 31615613]

[21] Serban KA, Pratte KA, Bowler RP. Protein biomarkers for COPD outcomes. Chest 2021; (21): S0012-3692. 00026-X [PMID: 33434499]

[22] Manon-Jensen T, Langholm LL, Rønnow SR, et al. End-product of fibrinogen is elevated in emphysematous chronic obstructive pulmonary disease and is predictive of mortality in the ECLIPSE cohort. Respir Med 2019; 160: 105814.

[http://dx.doi.org/10.1016/j.rmed.2019.105814] [PMID: 31739246]

[23] Kim TH, Oh DK, Oh YM, Lee SW, Do Lee S, Lee JS. Fibrinogen as a potential biomarker for clinical phenotype in patients with chronic obstructive pulmonary disease. J Thorac Dis 2018; 10(9): 5260-8. [http://dx.doi.org/10.21037/jtd.2018.08.52] [PMID: 30416773]

[24] Vilar R, Fish RJ, Casini A, Neerman-Arbez M. Fibrin(ogen) in human disease: both friend and foe. Haematologica 2020; 105(2): 284-96. [http://dx.doi.org/10.3324/haematol.2019.236901] [PMID: 31949010]

[25] Arellano-Orden E, Calero-Acuña C, Cordero JA, et al. Specific networks of plasma acute phase reactants are associated with the severity of chronic obstructive pulmonary disease: a case-control study. Int J Med Sci 2017; 14(1): 67-74.

[http://dx.doi.org/10.7150/ijms.16907] [PMID: 28138311]

[26] Valvi D, Mannino DM, Müllerova H, Tal-Singer R. Fibrinogen, chronic obstructive pulmonary disease (COPD) and outcomes in two United States cohorts. Int J Chron Obstruct Pulmon Dis 2012; 7 : 173-82.

[PMID: 22419864]

[27] Mannino DM, Ford ES, Redd SC. Obstructive and restrictive lung disease and markers of inflammation: data from the Third National Health and Nutrition Examination. Am J Med 2003; 114(9): 758-62. [http://dx.doi.org/10.1016/S0002-9343(03)00185-2] [PMID: 12829203]

[28] COPD Foundation. Avaialbe from: https://www.copdfoundation.org/

[29] Ingebrigtsen TS, Marott JL, Rode L, Vestbo J, Lange P, Nordestgaard BG. Fibrinogen and $\alpha 1$-antitrypsin in COPD exacerbations. Thorax 2015; 70(11): 1014-21.

[http://dx.doi.org/10.1136/thoraxjnl-2015-207561] [PMID: 26304913]

[30] Mannino DM, Valvi D, Mullerova H, Tal-Singer R. Fibrinogen, COPD and mortality in a nationally representative U.S. cohort. COPD 2012; 9(4): 359-66.

[http://dx.doi.org/10.3109/15412555.2012.668249] [PMID: 22489912]

[31] Lowe GD, Rumley A, Mackie IJ. Plasma fibrinogen. Ann Clin Biochem 2004; 41(Pt 6): 430-40.

[http://dx.doi.org/10.1258/0004563042466884] [PMID: 15588432]

[32] Ye D, Gajendra S, Lawyer G, et al. Inflammatory biomarkers and growth factors in saliva and gingival crevicular fluid of e-cigarette 
users, cigarette smokers, and dual smokers: A pilot study. J Periodontol 2020; 91(10): 1274-83.

[http://dx.doi.org/10.1002/JPER.19-0457] [PMID: 32052441]

[33] Niventhi A, Praveen D, Chowdary PR, Aanandhi MV. A review on clinical association of serum magnesium and serum fibrinogen levels with acute exacerbation of chronic obstructive pulmonary disease.
Drug Invention Today 2018; $1 ; 10(2)$

34] Rønnow SR, Sand JMB, Langholm LL, et al. Type IV collagen turnover is predictive of mortality in COPD: a comparison to fibrinogen in a prospective analysis of the ECLIPSE cohort. Respir Res 2019; 20(1): 63

[http://dx.doi.org/10.1186/s12931-019-1026-x] [PMID: 30935391]

\section{C) 2021 Ehsan et al.}

This is an open access article distributed under the terms of the Creative Commons Attribution 4.0 International Public License (CC-BY 4.0), a copy of which is available at: https://creativecommons.org/licenses/by/4.0/legalcode. This license permits unrestricted use, distribution, and reproduction in any medium, provided the original author and source are credited. 